Dhaka Univ. J. Biol. Sci. 25(2): 103-111, 2016 (July)

\title{
EPIDEMIOLOGY OF LYMPHATIC FILARIASIS IN NILPHAMARI DISTRICT, BANGLADESH
}

\author{
Md. Khalid Eakbal AniK*, Hamida Khanum, Iftekhar Ahmed Rizvi, \\ ShaHela Alam and Hasina BanU \\ Department of Zoology, University of Dhaka, Dhaka-1000, Bangladesh
}

Key words: Lymphetic Filariasis, Hydrocele, Risk factors

\begin{abstract}
The present study was carried out in Filaria Hospital of Nilphamari to find out the current status of lymphatic filariasis (LF) in Nilphamari district: An endemic area for lymphatic filariasis in Bangladesh. The inhabitants of the villages, the outdoor patients and hospitalized patients in Filaria Hospital were selected for the study. The current status and the prevalence of filariasis in Nilphamari district was $4.43 \%$, in Nilphamari Sadar was $3.25 \%$ and $4.10 \%$ in Sayedpur, $4.82 \%$ in Domar, $5.86 \%$ in Dimla, 3.85\% in Joldhaka and $4.70 \%$ in Kishoreganj. It was found that $58.84 \%$ filarial patients were male and $41.16 \%$ were female; highest prevalence of the disease was observed at the age group of 41 - 60 years. Illiteracy and poverty are the important social risk factors of this disease, about $45 \%$ patients were illiterate. Most of the infected patients were very poor and belong to low income group. Only $40.5 \%$ patients knew about filariasis. Only $26.1 \%$ patients used mosquito curtains. During the study period, it was found that $66.15 \%$ of hospitalized filarial patients were male and $33.85 \%$ were female, in the Filaria Hospital of Nilphamari. The highest outdoor patients in Nilphamari Hospital were of age group 40 - 59 years and $76.22 \%$ patients had hydrocele.
\end{abstract}

\section{Introduction}

Filariasis is a severely debilitating and stigmatizing disease caused by the parasite Wuchereria bancrofti, classic causative agent of this disease in humans, and is transmitted by mosquitoes. Culex mosquitoes are the main vectors for disease transmission in Bangladesh $^{(1)}$. This disease is manifested by enlargement of the limbs, scrotum, and other extremities; it is not the initial effect, but is the result of long-standing infection. As worms block the lymph vessels, edema occurs, and in times the deposition of connective tissue cells and fibers contribute to elephantiasis ${ }^{(1)}$. It is primarily a disease of the poor in tropical countries and is caused by three species of nematodes which are transmitted to humans by several genera of mosquitoes ${ }^{(2)}$. Forty million people have visible ailments, 120 million are infected in 80 countries and one billion live in the risk of infection ${ }^{(3)}$. India

*Author for correspondence: <Khalideakbalanik@gmail.com> 
has the highest burden with about $40 \%$ of global cases. Bangladesh is also considered as a major LF endemic country with 70 million population at risk.

Bangladesh, India, Maldives, Nepal and Sri Lanka harbor nearly half the world's lymphatic filariasis burden. Out of 64 districts of the country filariasis is endemic to 34 (based on ICT survey). The prevalence of the disease is high in the border districts of Panchgarh, Rangpur, Thakurgaon, Dinajpur, Nilphamari, Chapai Nowabgonj, Kurigram. Filariasis has been reported in different states of India ${ }^{(4)}$.

Demarquay (1863) described microfilariae of Wuchereria bancrofti and found what is now known as the embryonic form of microfilaria bancrofti in hydrocele fluid(5). Manson (1878) first demonstrated that mosquitoes were intermediate hosts for the parasite( ${ }^{(6)}$. Low (1900) determined the actual transmission method by discovering the presence of the worm in the proboscis of the mosquito vector ${ }^{(7)}$. Bourne (1888) discovered the adult male parasite ${ }^{(8)}$. Rao and Maplestone (1940) discovered the adults of B. malayi in India ${ }^{(9)}$. The pathology associated with lymphatic filariasis results from a complex interplay of the pathogenic potential of the parasite, the immune response of the host, and external ('complicating') bacterial and fungal infections.

In the present study, the main objectives were to find out the prevalence and clinical manifestations of filariasis with age, sex and socio-economic factors of the population, especially in the Nilphamari district; to assess the level of knowledge of the people about its causes and risk factors; to study the attitude of the people towards prevention and control measures are to be taken for lymphatic filariasis.

\section{Materials and Methods}

The present work was conducted within each domain of interest, which included the community members, service provider and program/policy domains of upazila health complexes. At the national level, the opinions of the professionals of filarial disease control programs were also included in interviews focusing on integration of their program.

Filaria Hospital of Savar, Filaria Hospital of Nilphamari, other upazila hospitals of Nilphamari, Nilphamari Sadar and Paurasava, Sayedpur, Domar, Dimla, Joldhaka and Kishoreganj upazilas of Nilphamari district were selected for the present study.

The study design was a multistage sampling with the following levels: district, upazila, road, hospitals and village. The rural areas and the villages were Topamari and Itakhola of Nilphamari Sadar and Paurasava, Kamarpukur and Belpukur of Sayedpur, Bamunia and Jorabari of Domar upazila, Chaknai and Goyabari of Dimla, Kathali and Mirganj of Joldhaka, Nitai and Putimari of Kishoreganj in Nilphamari district. 
The records of the investigation was done through a structured questionnaire filling and all the data were compiled. Finally tabulated data were analyzed and interpreted through the computer using the software MS Word.

The schedule consists of respondents demographic socio-economic information, variables were age, sex, educational qualification economic condition, knowledge about disease, their attitude and practice towards the prevention and control of the disease.

\section{Results and Discussion}

The present investigation was carried out among the rural people of the villages of six different unions of Nilphamari district and the outdoor patients of Filaria Hospitals of Nilphamari.

The current status of the filariasis among the people of six different unions of Nilphamari district including the Filaria hospital (Table 1). The prevalence of filarial patient on an average was $4.43 \%$, the highest (5.86\%) occurred in Dimla and the lowest $(3.25 \%)$ in Nilphamari Sadar (Table 1).

Table 1. Status of filariasis among the people of six union/upazila of Nilphamari district from 2011 to 2012.

\begin{tabular}{lcccc}
\hline $\begin{array}{l}\text { Union/ } \\
\text { upazila }\end{array}$ & $\begin{array}{c}\text { Total } \\
\text { families }\end{array}$ & $\begin{array}{c}\text { Total } \\
\text { members }\end{array}$ & $\begin{array}{c}\text { Total persons } \\
\text { affected }\end{array}$ & $\begin{array}{c}\text { Affected } \\
\text { persons (\%) }\end{array}$ \\
\hline Nilphamari Sadar & 6490 & 35662 & 1159 & 3.25 \\
Sayedpur & 803 & 4415 & 181 & 4.10 \\
Domar & 1268 & 6971 & 336 & 4.82 \\
Dimla & 2804 & 15410 & 903 & 5.86 \\
Joldhaka & 2652 & 14572 & 561 & 3.85 \\
Kishoreganj & 2714 & 14915 & 701 & 4.70 \\
Total & 16731 & 91945 & 3841 & 4.43 \\
\hline
\end{tabular}

On gender issue, maximum male (79.68\%) filarial patients were recorded in Joldhaka Union and the minimum male $(48.23 \%)$ was in Nilphamari Sadar Union, while the highest female $(52.77 \%)$ patients found in Nilphamari Sadar Union and the lowest (20.32\%) in Joldhaka Union (Fig. 1).

Regarding age group, the highest number of filarial patients (34.9\%) were observed in Nilphamari district in the age group of 41 - 60 years (Table 2).

The highest prevalence $(55.0 \%)$ of illiterate filarial patients identified in Joldhaka and the lowest $(35.0 \%)$ in Nilphamari Sadar. The filarial patients who could only sign their 
names were comparatively in higher percentage (37.0) from Kishoreganj and the lower (28.0) from Sayedpur (Table 3). There were few (3.5\%) infected persons who crossed the primary school level (Table 3). So, educational status is a great factor for this disease to be caused specially in the rural area(15).

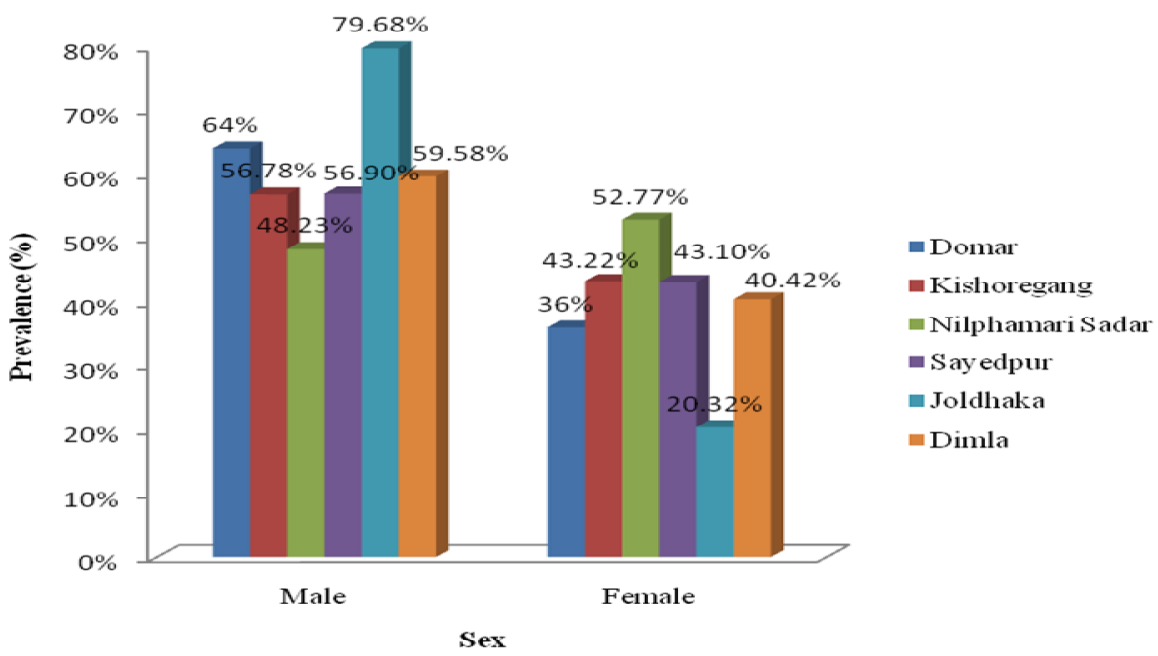

Fig. 1. Prevalence of patients according to sex in Nilphamari district from 2011 to 2012.

Table 2. Prevalence of filariasis among the patients in Nilphamari districts from 2011 to 2012 according to age groups.

\begin{tabular}{lccccc}
\hline \multirow{2}{*}{$\begin{array}{l}\text { Union/ } \\
\text { upazila }\end{array}$} & $\begin{array}{c}\text { Total } \\
\text { number }\end{array}$ & \multicolumn{4}{c}{ Age group (years) } \\
\cline { 3 - 6 } & & $1-20(\%)$ & $21-40(\%)$ & $41-60(\%)$ & $60+(\%)$ \\
\hline Domar & 336 & 20 & 30 & 34 & 16 \\
Kishoreganj & 701 & 17 & 32 & 33 & 18 \\
Nilphamari Sadar & 1159 & 7 & 24 & 39 & 20 \\
Sayedpur & 181 & 15 & 28 & 38 & 19 \\
Joldhaka & 561 & 18 & 27 & 36 & 19 \\
Dimla & 903 & 19 & 36 & 30 & 15 \\
Total (\%) & 3841 & 17.78 & 29.41 & 34.9 & 17.9 \\
\hline
\end{tabular}

In Nilphamari district, only 40.5\% (1557) patients knew about filariasis. On the other hand, the largest portion, 59.5\% patients were ignorant regarding filariasis. So, lack of knowledge was also a major factor for transmission of filariasis in the district. 
In Nilphamari district, $26.1 \%$ of the infected patients used mosquito net. The highest monthly income of $47.02 \%$ was Tk. 1000-2000, 36.06\% earned Tk. 2000-3000 monthly, $12.91 \%$ earned Tk. 3000-4000 monthly. Only 4.01\% were capable of earning above Tk. 4000 monthly. So, the rural people of Nilphamari district could not afford to buy mosquito net, aerosol or mosquito coil for the protection from mosquito bites.

During July, 2011 to June, 2012 in the Filaria Hospital of Nilphamari, higher prevalence of male $(7.27 \%)$ and female $(3.73 \%)$ patients were recorded in June, 2012; while, comparatively lower prevalence of male $(4.21 \%)$ and female patients $(2.10 \%)$ were in October, 2011. So, it was evident that the prevalence of filariasis increased in summer and gradually decreased towards the months of winter (Fig. 2a). During the study period $66.15 \%$ male and $33.85 \%$ female patients were found in the hospital (Fig. $2 b)$.

Table 3. Educational status of the filarial patients in Nilphamari district.

\begin{tabular}{lccccc}
\hline Union/ & $\begin{array}{c}\text { Total } \\
\text { upazila }\end{array}$ & \multicolumn{4}{c}{ Educational status } \\
\cline { 3 - 5 } & number & $\begin{array}{c}\text { Illiterate } \\
(\%)\end{array}$ & $\begin{array}{c}\text { Can sign } \\
\text { only }(\%)\end{array}$ & $\begin{array}{c}\text { Primary } \\
(\%)\end{array}$ & $\begin{array}{c}\text { Above } \\
\text { primary }(\%)\end{array}$ \\
\hline Domar & 336 & 47 & 32 & 20 & 1 \\
Kishoreganj & 701 & 46 & 37 & 17 & 0 \\
Nilphamari Sadar & 1159 & 35 & 30 & 25 & 10 \\
Sayedpur & 181 & 42 & 28 & 24 & 5 \\
Joldhaka & 561 & 55 & 33 & 12 & 0 \\
Dimla & 903 & 51 & 35 & 14 & 0 \\
\hline
\end{tabular}

Lymphedema, Hydrocele and other symptoms due to filariasis at different age groups in the Filaria hospital of Nilphamari district are shown in Fig. 3. Lymphadema with lower limb was higher at the age group from 40 to 60 years and lower at early and older ages (Fig. 3). This observation indicates that older patients showed the symptoms more than new ones and filaria was decreasing gradually. During the study period, among the out door patients in Nilphamari Filaria Hospital, the prevalence of Lymphedema with lower limbs was $30.52 \%$, Hydrocele $66.34 \%$ and others were $3.14 \%$ (Fig. 3).

While genital damage (hydroceles) and lymphoedema or elephantiasis were the most recognizable clinical entities associated with lymphatic filarial infections, there are much earlier stages of lymphatic pathology and dysfunction. Of all the individuals with lymphatic filariasis less than half appear clinically asymptomatic, though they had microfilaria circulating in their blood and yet all have hidden damage to their lymphatic and renal systems (heamaturia and proteinuria) ${ }^{(19) .}$ 


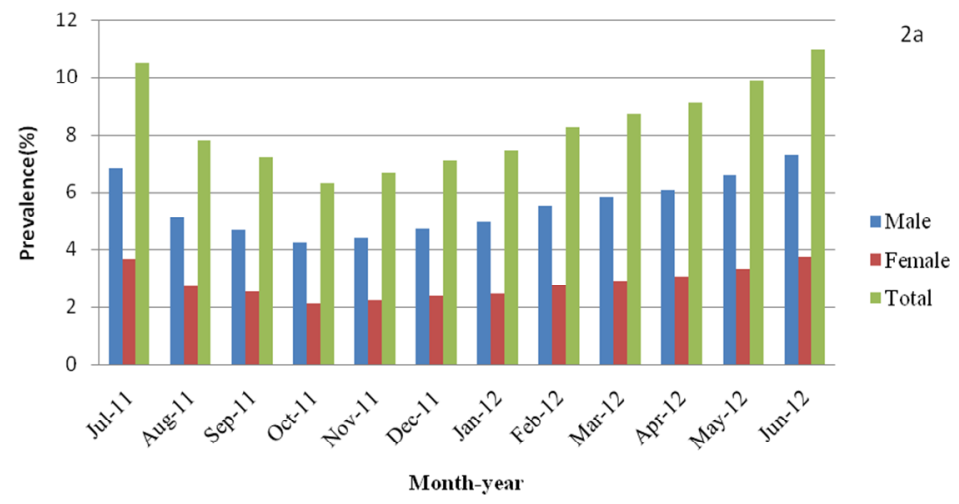

$2 \mathrm{~b}$

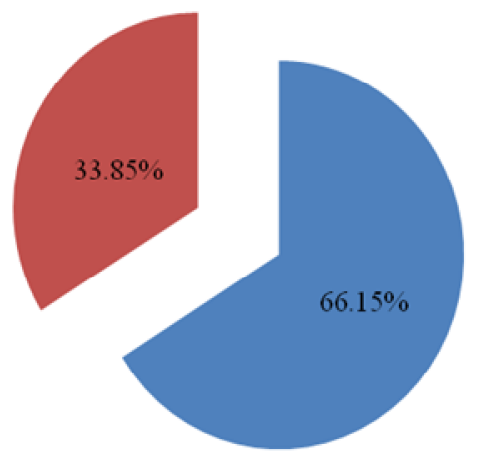

nale

a Female

Fig. 2a,b. Distribution of filarial patients in Filaria Hospital of Nilphamari during July, 2011 to June, 2012.

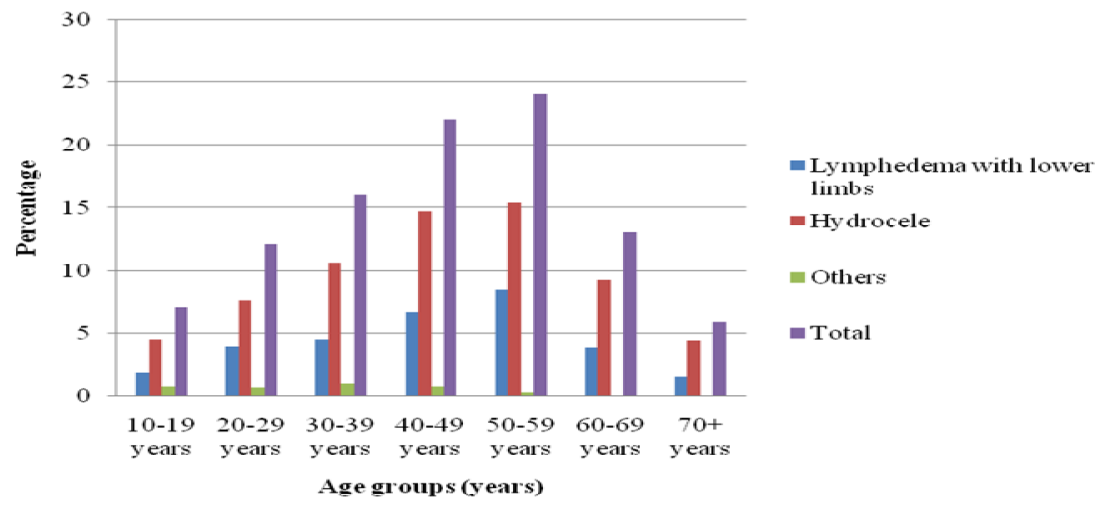

Fig. 3. Signs and symptoms of filariasis manifested in different age groups of patients in Filaria Hospital of Nilphamari. 
WHO estimated the number of people at risk from lymphatic filariasis (49 million) (annual report 2002) in mainly northwestern Bangladesh(10). Lymphatic filariasis is a national problem of Bangladesh.

There are 32 filariasis endemic districts in Bangladesh. Wolf and Aslam (1972) surveyed for night blood microfilaria in Dinajpur district, to have the highest prevalence of filariasis ${ }^{(11)}$. A filariasis survey of the entire Thakurgaon upazila of Dinajpur district was carried out by Bary et al.(12). Examinations of 9624 inhabitants revealed a microfilaria rate of $16.8 \%$ and a disease rate of $10.1 \%$. Concurrent with their investigations, in 1983 a survey was carried out by NIPSOM in Thakurgaon district; it was found that the microfilaria rate was $27.13 \%{ }^{(13)}$.

Culex quinquefasciatus lay eggs in domestic collection of water and such places as flooded open cement drains, flooded latrines, overflow water from houses, kitchens, ground pools, ditches, and shallow wells, rarely in tree holes or bamboos, not jungle pools, stream pools if far from human habitants ${ }^{(14)}$. About $27 \%$ (1004) patients used mosquito curtain.

Electricity is not available in many villages. So, most of the villagers do not have television, radio, etc. As a result they did not get the information of this disease from the TV or radio. Moreover, electric fan indirectly helps to keep away the mosquitoes especially during the summer ${ }^{(15)}$.

According to WHO (1992), transmission of filariasis normally occur in those areas where the population densities are much higher along with deficiencies in urban infrastructure. It was found in the study area that the population was over crowded. So filariasis could easily spread in this area(16).

In the present study it was found that most of the patients were ignorant regarding filariasis treatment and it indicates that ignorance is another social risk factor of the disease "filariasis". Government should take proper steps to control this disease ${ }^{(17)}$.

\section{Conclusion}

The socio-economic factors like poverty, illiteracy etc. are vital reasons of the disease transmission and higher prevalence. Government should take proper steps, such as increasing awareness, distributing of leaflet having the information about fllariasis, its control and prevention, appointment of sufficient health workers to the endemic areas to ensure the proper health management, broadcasting the mesures should be taken to prevent, cure and control of the disease on TV, radio, etc. to increase the awareness about filariasis. 


\section{Acknowledgements}

The authors are grateful to the Chairman of the Department of Zoology, University of

Dhaka for providing facilities. They are indebted to the patients, doctors and staff of Nilphamari Filaria Hospital for their support.

\section{References}

1. Thomas CF 1986. General Parasitology, 2nd edition, Academic press college division, Harcourt Brace Jovanovich, Publishers, New York. pp. 538-539.

2. Molyneux DH, M Bradley, A Hoerauf, D Kyelem and MJ Taylor 2003. Mass drug treatment for lymphatic filariasis and onchocerciasis. Trends Parasitol. 19: 516-522.

3. Ottesen EA 2000. The global programme to eliminate lymphatic filariasis. Tropical Medicine \& International Health 5(9): 591-594.

4. Khanum H, SSNN Sarker, MM Hossain, S Musa and R Farhana 2012. Occurrence of hydrocoele in Thakurgaon, an epidemic prone area of Bangladesh. J. Nat. Hist. (India) 8(1): 11-17.

5. Demarquay M 1863. Note sur une tumeur des bourses contenant un liquide laiteux (galactocela de vidal) et refermant des petits etres vermiformes que I'on peut considerer comme des helminths hematoides a I’etat d`embryon. Gaz. Med. Pans. 18: 665-667.

6. Manson P 1878. Further observation on filarial Sanguinis hominis. Medical Reports, no. 14, China Imperial Maritime Customs, Shanghai pp. 1-26.

7. Low GC 1900. A recent observation on Filaria nocturna in Culex, probable mode of infection in man. Br. Med. J. 1: 1456-1457.

8. Bourne AG 1888. A note on Filaria sanguinis hominis: with a description of the male specimen. British Medical Journal 1: 1050-1051.

9. Rao SS and PA Maplestone 1940. The adult of Microfilaria malayi Brug, 1927. Ind. Med. Gazette 75: $159-160$.

10. WHO 2002. Lymphatic Filariasis: The Disease and Its Control. Technical Report 71: 21-323.

11. Wolf MS and KM Aslam 1972. Bancroftian filariasis in two villages in two villages in Dinajpur district, East Pakistan.1. Entomological investigations. Am. J. Trop. Med. Hyg. 21: 30-37.

12. Bary C, A Ahmed and AQ Khan 1971. Endemic filariasis in Thakurgaon, East Pakistan. Am. J. Trop. Med. Hyg. 20: 592-597

13. Ahmed TU, NP Maheswary, NI Khan 1986. Filariasis in Mirpur area of Dhaka city. BMRC Bull. Dec. pp. 83-94.

14. Barraud PJ 1934. The fauna of British India, including Ceylon and Burma. Diptera. Taylor and Francis. Red Lion Court, Fleet Street, London 5: 55.

15. Khanum H and S Islam 2013. (DEC.) Prevalence and risk factors of filariasis in endemic districts of Bangladesh. 23rd National Congress of Parasitology. Dept. of Zoology, Kalyani University, Kalyani, West Bengal pp. 231-241.

16. WHO 1992. Lymphatic filariasis: the disease and its control. Fifth report, expert committee on filariasis, Geneva p. 71.

17. Rahman ABM M, H Khanum, M Chowdhury and R Farhana 2008. Current status and endemicity of filariasis in Thakurgaon, northern part of Bangladesh. Bangladesh J. Zool. 36(1): 111-116 
18. WHO 2004. Lymphatic filariasis: progress of disability prevention activities. Weekly Epidemiological Record 79: 417-24.

19. Khanum H, J Abedin and M Hossain 2015. Application of technologies for diagnosis, treatment, prevention and control of malaria, kala-azar and filaria in endemic areas of Bangladesh. Proceedings of $3^{\text {rd }}$ International Conference on Advances in Applied Science and Environmental Engineering, 11-12 April, 2015, Kuala Lumpur, Malaysia.

20. Manson-Bahs PH 1945. Manson's Tropical Diseases: A manual of the diseases of worm climates. 12th edn. pp. 703-704. Cassell and Company, London.

(Manuscript received on 9 August, 2015; revised on 14 July, 2016) 